\title{
A influência da estrutura organizacional nos controles internos de uma fundação para pesquisa, prevenção e assistência do câncer do interior paulista
}

\author{
The influence of the organizational structure \\ on the internal controls of a foundation for cancer research, \\ prevention and care in the interior of the state of São Paulo, Brazil
}

Carlos Alberto Grespan Bonacim ${ }^{1}$

André Luís Salgado ${ }^{1}$

Lumila Souza Girioli ${ }^{1}$

Adriana M aria Procópio de Araujo ${ }^{1}$

\footnotetext{
${ }^{1}$ FaculdadedeEconomia, Administração e

ContabilidadedeRibeirão Preto, Universidade deSão Paulo. Av. dos Bandeirantes 3900, sala 5, bloco A, M onte Alegre. 14040-900

Ribeirão Preto SP.

carlosbonacim@usp.br
}

Abstract This work focuses on a discussion about the extent to which the level of organizational structure interferes in the internal control practices of non-governmental organizations (NGOs), especially those related to health. The objective of this work was to observe the efficiency of the internal control tests applied within the organizational structure of the Foundation for Cancer Research, Prevention and Care, checking the reliability of the accounting records and operational controls. A case study in a third sector health organization was the chosen methodology. The case study involved company interviews and the analysis of confidential reports. After an evaluation of the organizational structure (of the relations between officials and volunteers) and the application of evaluation proceedings on the quality of the internal controls, the extent to which the organizational structure interferes with the internal control practices of the hospital was assessed. It was revealed that therearestructured mechanisms of control in the institution, however the implementation of these controls is inadequately performed. It was further detected that thelevel of the organizational structure does indeed interfere in internal control practices at the entity.

Key words Third sector entities, Foundation for Cancer Research, Prevention and Care, Internal controls, Organizational structure
Resumo 0 estudo centra-sena discussão de que o nível da estrutura organizacional interfere nas práticas de controle interno das organizações não governamentais(O NGs), sobretudo ligadasà saúde. 0 objetivo deste trabalho foi o de observar a eficiência dos testes de controle interno aplicados dentro de uma estrutura organizacional da Fundação para Pesquisa, Prevenção e Assistência do Câncer, verificando a confiabilidade nos relatórios contábeis e controles operacionais. Como metodologia, realizou-se um estudo de caso em uma organização desaúde do terceiro setor. 0 estudo de caso ocorreu por meio de entrevistas e análises de relatórios confidenciais. Diante de uma avaliação da estrutura organizacional (das relações entre funcionários e voluntários) e da aplicação de procedimentos de avaliação da qualidade dos controles internos, avaliou-se o quanto o nível da estrutura organizacional interfere nas práticas de controle interno do hospital. O bservou-se que existem mecanismos de controle estruturados na instituição, porém a execução desses controles deixa a desejar. Pode-se constatar também que o nível da estrutura organizacional interfere, sim, nas práticas de controle interno da entidade.

Palavras-chave Entidades do tercei ro setor, Fundação para Pesquisa, Prevenção e Assistência do Câncer, Controle interno, Estrutura organizacional 
Introdução

0 terceiro setor é formado por entidades sem fins lucrativos e não governamentais cuja atuação pode beneficiar tanto um público amplo quanto os próprios membros. Parte desse setor, as organizações não governamentais (ONGs), apresentam características que Ihes são específicas em decorrência do contexto no qual surgiram. Essas entidades, em especial as da área da saúde, têm seus recursos provenientes principalmente de doações e/ou financiamentos, seja de organizações de cooperação internacional, seja de governos, ou mesmo de doações individuais.

Para que desenvolvam suas atividades, essas entidades precisam aplicar de forma eficiente os recursos que Ihes são destinados, ou seja, a eficiência na utilização dos recursos é uma variável importante para a manutenção do fluxo regular de financiamentos que permite a continuidade das atividades desenvolvidas pelas $0 \mathrm{NGs}$.

Muitas das organizações do terceiro setor surgiram por iniciativas de pessoas sem experiência em gestão e apresentam muitas dificuldades na sua administraçãa ${ }^{1}$. A escassez de recursos nessas entidades, visto que a maior parte de las depende da solidariedade alheia, exige, ainda mais, uma gestão eficiente e controle interno.

M as, na prática, essa gestão eficienteraramente acontece. A deficiência na gestão ${ }^{2}$ é um dos fatores de restrição a um maior desenvolvimento do terceiro setor. Outro fator importante: uma boa gestão dos controles internos pode ser uma importanteferramenta para a utilização eficientedos recursos, escassos na maioria dos casos, que são aplicados em ONGs. No entanto, sua implementação precisa considerar os tipos das estruturas organizacionais predominantes nessas entidades

A seguinte premissa orienta esteestudo: o nível da estrutura organizacional interfere nas práticas de controle interno das ONGs.

Há um virtual consenso entre estudiosos e pessoas envolvidas de que as organizações sem fins lucrativos ${ }^{3}$ ligadas à saúde no Brasil ${ }^{4}$ estão passando por dificuldades no gerenciamento do setor, e que 0 aperfeiçoamento da gestão $0^{5}$ é um caminho necessário para "o atingir" de melhores resultados.

Como os testes de controle interno podem auxiliar a identificar o comportamento gerencial da estrutura organizacional e colaborar para 0 seu aperfeiçoamento?

0 estudo pretende observar a eficiência dos testes de controle interno, aplicada em uma estrutura organizacional pertencente ao terceiro setor, verificando a confiabilidade nos relatórios contábeis, financeiros e operacionais.

Uma contextualização da crise no setor de saúde curativa: as lacunas do Estado/Sistema Único de Saúde (SUS)

0 enfraquecimento da seguridadesocial naAmé rica Latina ${ }^{6}$ (o que inclui a realidade brasileira) proporcionou dificuldades associadas à manutenção dessas instituições, impedindo que os hospitais exerçam plenamente suas funções primordiais ${ }^{7}$ : a atenção à saúde da comunidade e a formação de profissionais, e a produção de conhecimento e o desenvolvimento de tecnologia para a área da saúde.

A consequência imediata desse enfraquecimento seria um aumento da participação de re cursos da iniciativa privada, criando instituições deeconomia mista (partedo capital público, parte privado) tal como ocorreu em outros setores como de telecomunicações, energia elétrica etc., antes do fenômeno das privatizações.

Contudo, em 1992, 46,70\% dos hospitais integrados ao SUS eram de natureza particular, ou seja, praticamente metade dos convênios de prestação de serviços assistenciais do SUS estavam estabelecidos com hospitais privados. Em 2003, este percentual caiu para $30,46 \%$. Esta redução ${ }^{8}$ de $16,24 \%$ representa uma demanda potencial para as entidades do terceiro setor ligadas à área da saúde.

A lógica seria que a iniciativa privada "ocupasse" com eficiência o espaço deixado pelo Estado. Desta forma, sendo eficientes, os hospitais privados conseguiriam ser viáveis economicamente, mesmo custeados pelo SUS.

Entretanto, o que se verificou foi uma redução na participação de hospitais privados conveniados, ou seja, uma "falta de interesse" do capital privado ${ }^{9}$. Muitos pesquisadores ${ }^{10}$ explicam o porquê desta "falta de interesse" dos investimentos deiniciativa privada para com o setor de saúde, quando apresentaram uma "análise da relação entre os prestadores privados de serviços de saúde e o SU S", em que demonstram os reflexos da reestruturação da rede hospitalar brasileira na década de 90 - considerando-se que na década de 90 aproximadamente $10,50 \%$ dos hospitais privados romperam o contrato com o SUS, com a justificativa de que os recursos repassados pelo Estado eram insuficientes para a manutenção de suas atividades eque, portanto, inviabilizariam financeiramentea prestação dos serviços. 
Em especial foram afetados os hospitais públicos, pois em tese foi a rede hospitalar exclusivamente pública que absorveu a demanda repelida (10,50\%) pelos hospitais particulares. 0 resultado prático disso são as filas intermináveis, a precariedade nos atendimentos e nas condições de trabaIho dos profissionais dessas instituições etc.

O terceiro setor

esua estrutura organizacional

As ON Gs representam enti dades que fazem parte do terceiro setor, possuem fins não lucrativos e são de direito privado. A literatura ${ }^{11}$ considera que as ON Gs representam um dos componentes mais importantes do terceiro setor brasileiro, sendo o termo mais difundido ${ }^{12}$.

As organizações não governamentais vêm passando por desafios ao longo de sua existência que vão se modificando à medida que mudanças no contexto social epolítico no qual estão inseridas também passam por mudanças. Os principais desafios pelos quais passaram essas entidades na década de $90^{\circ}$ são: (1) sair do micro para o macro, isto é, não limitar suas ações a microrregiões, e sim contribuir com sua experiência para o desenvolvimento macro; (2) sair do privado para o público, deixando de atuar na clandestinidade para atuar de forma mais transparente, divulgando ao público o que são, por quelutam, o que propõem; e (3) passar da resistência à proposta, ou seja, da ação contra o Estado e à margem do mercado para uma ação participante.

Assim, as ON Gs brasileiras passam por um momento de dificuldades quanto à obtenção de recursos ${ }^{13}$. N esse contexto, uma das tendências das ON Gs é a preocupação crescente com a sustentabilidade ${ }^{14}$.

As ONGs estão passando por alguns problemas estruturais de ordem de gestão. Embora a gestão das organizações não governamentais venha despertando interesse nos meios acadêmicos nos últimos anos ${ }^{15}$, tendo em vista o crescimento e a diversificação do setor e as mudanças organizacionais observadas nessas instituições, pouco se sabe sobre as práticas de gestão dessas organizações no Brasil. Um dos motivos da escassez de pesquisas empíricas acerca da gestão de ONGs decorre do fato de que essas organizações exercem diferentes papéise há dificuldades conceituais para defini-las, compará-las: uma das formas de verificar as estruturas organizacionais está em percorrer os níveis de controle interno. Assim, os procedimentos de gerenciamento são realizados em todos os níveis hierárquicos, desde gestores até voluntários e funcionários, colaborando de forma efetiva na estrutura organizacional.

Apesar das dificuldades de comparar as práticas gerenciais e defini-las, acreditamos que as técnicas de auditoria de controles internos são ferramentas eficazes para iniciar os trabalhos e mapear a estrutura organizacional das variadas O N Gs existentes no Brasil. A próxima seção ilustra as técnicas de controle interno aplicadas no estudo.

\section{Controles internos}

Esse procedimento tem a finalidade de conferir a precisão e a confiabilidade dos dados contábeis, promover a eficiência operacional e encorajar a aderência às políticas administrativas prescritas. Ao aplicarmos esta definição, estaremos reconhecendo que um sistema de controle interno ${ }^{16}$ se estende além dos assuntos que se relacionam diretamente com as funções da contabilidade edos departamentos financeiros.

0 conceito é bastante abrangente. Podemos verificar que o controle interno não só abrange os aspectos contábeis e financeiros ${ }^{17}$ como também os operacionais dentro da organização.

Finalidades da avaliação

dos controles internos

As finalidades da avaliação dos controles internos são as seguintes: (1) determinar o grau de abrangência do trabal ho a ser realizado em face de estrutura existentena entidade; e(2) definir claramentea natureza dos procedimentosa serem adotados, a extensão e a profundidade nas aplicações dos exames e o momento de sua aplicação.

É importante salientar que tais recomendações devem ser convenientemente anal isadas para sua aplicabilidade à empresa e que possam, por meio de recomendações, dar efetiva contribuição ao aperfeiçoamento administrativo e contábil da empresa.

Ao avaliar o controle interno, deve-se objetivar a identificação de pontos (erros ou irregularidades) que possam trazer distorções nas demonstrações contábeis. Para tanto, deve-se, ao avaliar os controles internos: (1) considerar os tipos de erros e/ou irregularidades que poderiam ou que possam ocorrer, com relação à estrutura do sistema de controle vigente; e(2) verificar se todos os procedimentos emanados da administração são seguidos pelos diversos níveis hierárquicos. 


\section{Procedimentos metodológicos}

Segundo a literatura ${ }^{18}$, atipologia de delineamento de uma pesquisa pode ser agrupada em três categorias: a pesquisa quanto aos objetivos, quanto aos procedimentos e quanto à abordagem do problema.

Quanto aos objetivos, a presente pesquisa é descritiva, poistem como principal objetivo descrever características de determinada população ou fenômeno ou o estabelecimento de relações entre as variáveis. Uma de suas características mais significativas está na utilização de técnicas padronizadas de coletas de dados. No presente trabalho, utiliza-se a técnica da auditoria: o teste de aderência ou observância.

Quanto à estratégia de pesquisa, trata-se um caso de estudo ${ }^{19}$. Cabe ressaltar que trata-se de um espaço para verificar se as proposições de uma premissa são válidas nele. 0 caso de estudo foi realizado na Fundação para Pesquisa, Prevenção eAssistência do Câncer de Ribeirão Preto (SP) - unidade de análise.

Por sua vez, a abordagem do problema na pesquisa é qualitativa ${ }^{20}$. Isso se justifica devido ao fato de que os estudos que empregam uma me todologia qualitativa podem descrever a complexidade de determinado problema, analisar a interação de certas variáveis, compreender e classificar processos dinâmicos vividos por grupos sociais ${ }^{20}$.

Ressalta-se também que o estudo pode contribuir no processo de mudança de determinado grupo e possibilitar, em maior nível de profundidade, o entendimento das particularidades do comportamento dos indivíduos. Nesse trabalho, amelhorianos controles internos vem justamente contribuir nesse processo de mudança.

Testes de observância ou aderência

A realização detestes deaderência tem a finalidade de confirmar as observações feitas pelo auditor em seus exames preliminares sobre o controle interno, como também confirmar as informações, verbais e escritas, fornecidas pelo pessoal da empresa e por sua administração.

Os testes devem ser abrangentes 0 suficiente para dar garantia e segurança ao trabalho, dando-Ihe a convicção do grau de dificuldade que terá para a realização dele e fornecendo os ele mentos indispensáveis para definir natureza, extensão e profundidade dos procedimentos de auditoria a serem aplicados como informação à controladoria, instalando diretrizes para aperfeiçoar seus controles.
As técnicas mais apropriadas para a avaliação dos controles internos de uma entidade ou departamento são: (1) observação pessoal (dire ta); (2) entrevistas; (3) questionários; e (4) exames dos trabalhos realizados pela auditoria interna (quando houver).

Observação pessoal

Esta técnica éespecialmenteimportante para se avaliar seo sistema de controle realmentefunciona como previsto. Funcionários podem ou não seguir as instruções (muitas vezes, os regulamentos e diretrizes da entidade podem ser considerados muito rígidos ou burocratizados, e ignorados completamente). A equipe de auditoria deve procurar observar se os servidores estão realmente colocando em prática os procedimentos de controle estabelecidos (por exemplo: a observação do ambiente de trabalho pode permitir a constatação de que as senhas individuais deacesso a um sistema computacional não estão sendo mantidas em sigilo como previsto, sendo utilizadas indistintamente por todos os componentes de uma repartição).

\section{Entrevistas e questionários}

A equipe de auditoria deve criar, na fase de planejamento, um plano deentrevistas e/ou questionários envolvendo os principais agentes responsáveis pelos processos de licitação e contrato da entidade auditada. As perguntas devem ser elaboradas de forma a extrair o máximo de informação relevante no tempo disponível, devendo ser ajustadas, ao longo da entrevista, em razão das respostas e das reações não verbais dos entrevistados ${ }^{21}$.

Mapas de processos

0 mapeamento de processo é a representação de um processo de trabalho por meio deuma sequência de passos necessários para se visualizar o caminho ordinário dos processos de controle. Um processo corresponde a uma sequência ordenada de etapas de trabalho, podendo ser decomposta em atividades específicas, medidas, modeladas e aprimoradas, bem como redesenhadas completamente.

A técnica de mapeamento de processo fornece uma representação descritiva das operações em análise, evidenciando a sequência de atividades, os atores envolvidos, os prazos fixados e 0 fluxo de documentos.

0 diagrama do mapa de processo pode ter diversos graus de detal hamento, segundo o propósito para o qual ele é elaborado. As principais 
informações que ele deve fornecer são: (1) descrição das atividades; (2) pontos de tomada de decisão; (3) movimentos de informação e de documentos; (4) pontos de controle; (5) prazos; e (6) documentos e relações entre as diversas etapas do processo.

\section{Exame dos trabalhos}

realizados pela auditoria interna

Ao avaliar os controles internos da organização como um todo, ou os controles específicos de uma área ou departamento, a equipe de auditoria deve proceder a uma análise dos trabalhos efetuados pela auditoria interna naquela área.

Esse exame permite obter-se uma ideia geral de como os controles internos estão estruturados, quais seus pontos fortes e vulnerabilidades, ecomo a auditoria interna tem atuado para aprimorá-los. A análise dos relatórios, recomendações e acompanhamentos ${ }^{22}$ realizados pela auditoria interna pode ajudar a equipe a estabelecer prioridades e a determinar o grau de abrangência e profundidade da análise a ser efetuada nos controles da entidade.

Como técnica de coleta dos dados, fontes e evidências, recorreu-se, além da pesquisa documental, à entrevista semiestruturada. 0 protocolo de pesquisa e o roteiro de entrevista foram encaminhados ao Comitê de Ética e Pesquisa da referida fundação, e após parecer favorável, foram aplicados na unidade de análise.
Sobre a Fundação para Pesquisa, Prevenção e Assistência do Câncer

A Fundação para Pesquisa, Prevenção e Assistência do Câncer é uma fundação de direito privado, sem fins lucrativos, com sede no interior do Estado de São Paulo. Tem existência por prazo indeterminado, regendo-se por estatuto, por seu regimento interno e pela legislação que lhe for aplicável.

Os objetivos da fundação são os de promover a prevenção, o diagnóstico e o tratamento do câncer, além de fomentar cursos, simpósios, seminários, conferências e estudos visando ao ensino eà difusão dos conhecimentos pertinentesà oncologia.

Atualmente, existem 11 funcionários remunerados e 130 voluntários com participações indiretas e dez voluntários com participações diretas. A diretoria é composta pelo diretor-presidente, diretor-financeiro, diretor-clínico e diretor de relações externas.

Foram realizados al gumas campanhas e projetos iniciados em 2005, como a construção da sede própria do Hospital do Câncer, o Projeto M amaM óvel, o Projeto Vida Feliz e o Projeto M amal magem, iniciado em 2006. Além disso, a fundação realizou diversos eventos e campanhas para arrecadação de fundos (Quadro 1).

\section{Análise dos testes}

Os controles internos foram relatados pelo responsável da controladoria por meio de entrevista. Verificamos a autenticidade desses controles com um dos procedimentos mais utilizados na auditoria: o teste de aderência.

Quadro 1. Caracterização da estrutura organizacional na Fundação para Pesquisa, Prevenção e Assistência do Câncer.

\begin{tabular}{|l|l|l|}
\hline \multicolumn{1}{|c|}{ Parâmetros de classificação } & \multicolumn{1}{|c|}{ Entidade do terceiro setor } & \multicolumn{1}{c|}{ Grupo voluntário } \\
\hline Especialização dos serviços & Especialização horizontal & Especialização vertical \\
\hline Treinamento e doutrinação & $\begin{array}{l}\text { M uito treinamento e alguma } \\
\text { doutrinação }\end{array}$ & $\begin{array}{l}\text { Pouco treinamento e muita } \\
\text { doutrinação }\end{array}$ \\
\hline $\begin{array}{l}\text { Formalização do comportamento, } \\
\text { burocrático/orgânico }\end{array}$ & Muita formalização, burocrática & Pouca formalização, orgânica \\
\hline Agrupamento & Funcional & Funcional e mercado \\
\hline Sistema de planejamento e controle & Pouco planejamento e controle & Algum planejamento e controle \\
\hline Descentralização & Descentralização seletiva & Descentralização vertical \\
\hline
\end{tabular}

Fonte: elaborado pelosautores. 
Com referência ao que foi relatado, constatou-se um controle satisfatório, porém o mesmo não foi observado no teste de aderência. Descre veu-se todo o processo de controle de compras e contas a pagar a título de ilustração (Figura 1).

0 processo tem início quando a farmacêutica responsável pelo estoque faz o levantamento dos medicamentos faltantes. Esse levantamento éfeito observando-se visualmenteo estoque. Não existe um controle efetivo sobre ele nem conferência por parte de outra pessoa. Em seguida é feita uma cotação em três distribuidoras, ressaltando que é cotado o melhor medicamento ge nérico, característica do excelente tratamento dado aos pacientes da entidade. Então elaborase uma planilha com os três preços cotados.

Não observamos provas como fax e e-mails das empresas cotadas, apenas uma planilha elaborada pela responsável. A farmacêutica seleciona o menor preço e encaminha para aprovação do diretor técnico e da controladoria. Assim, a compra éautorizada e efetuada pela própria farmacêutica. Observamos quenão constava na pla- nilha a assinatura do diretor-técnico, apenas a da controladoria. Quando a medicação é entregue, a conferência também éfeita pela farmacêutica. Como todo o processo é realizado por uma única pessoa, isso gera margem para erros e possíveis irregularidades, como desvios de medicamentos, por exemplo.

No final do mês, a farmacêutica elabora uma planilha com os medicamentos restantes no estoque para que a controladoria apure o custo. A controladoria consegue justificar a entrada do medicamento pela nota fiscal, porém não justifica a saída, por falta de controle.

Por sua vez, o custo é apurado por diferença. Inclusive a auditoria externa está ajudando a elaborar mecanismos melhores e mais eficazes para controle do estoquee apuração do custo. Também não são feitos inventários periódicos na entidade.

A pesar de haver uma estrutura administrativa relativamente grande, fazem-se poucos controlesfinanceiros, esão controles básicos. A controladoria acompanha os fluxos financeiros e de compras. Elabora-se um fluxo de caixa mensal

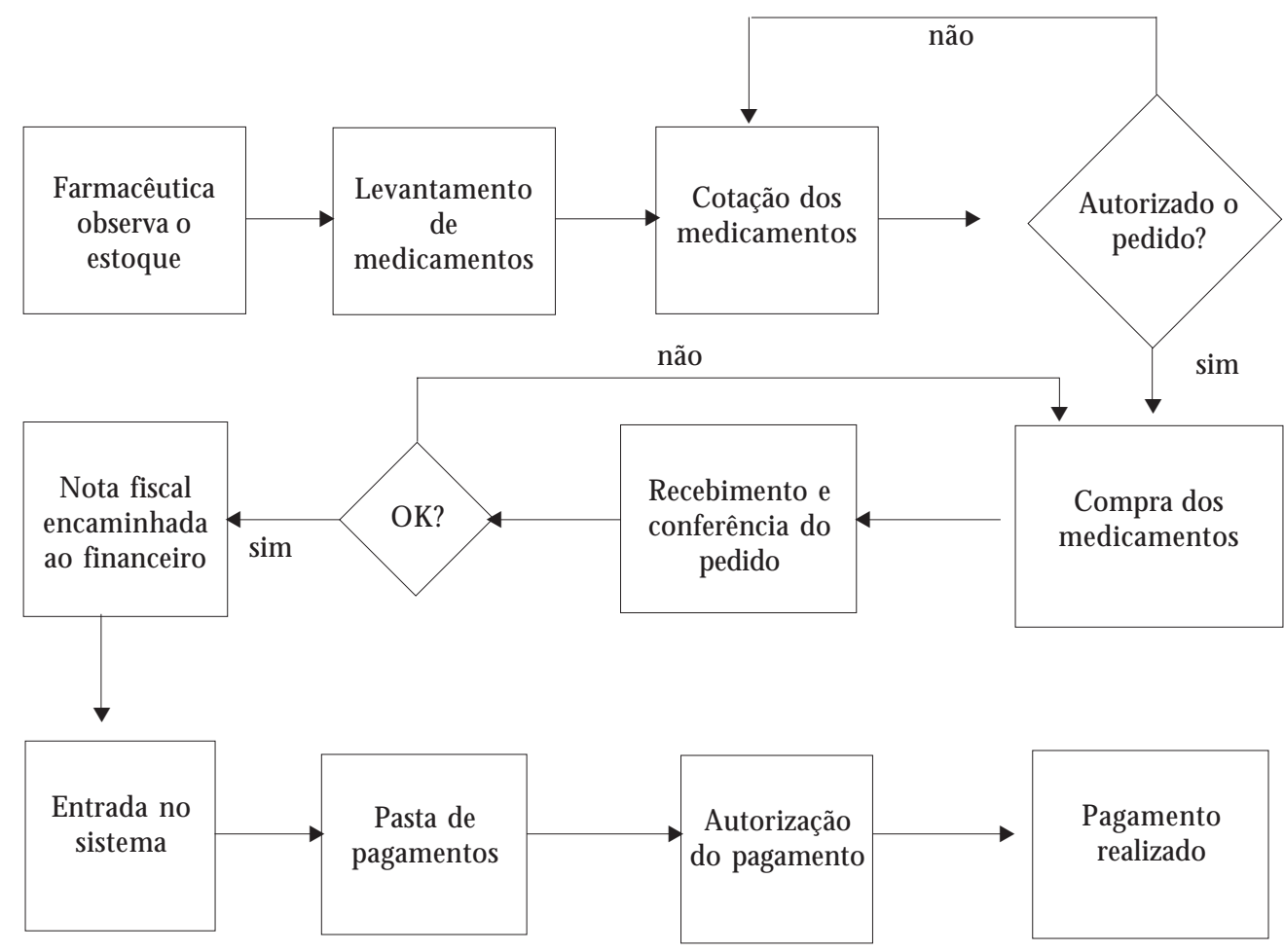

Figura 1. Fluxograma do processo de compras e pagamentos. 
ou semanal (quando necessário), um relatório com toda a movimentação financeira, balancetes mensais e balanço social anual. As demonstrações do final do ano são auditadas por exigência do Conselho Administrativo e não exigência legal, e depois publicadas.

Um ponto positivo é a divulgação dos resultados contábeis para todos os membros da organização e sua discussão exaustiva na tentativa de buscar melhorias. De fato, foi possível verificar, nos murai s internos do hospital, os relatórios financeiros afixados.

Com relação ao sistema de contas a pagar, a controladoria recebe as notas fiscais e dá a entrada no sistema. No dia do vencimento da nota, o responsável pela controladoria confronta o sistema com a pasta que contém os respectivos boletos.

Todos os pagamentos são realizados com cheques assinados semanalmente pela diretoria. Existe um caixa de baixo valor. Toda a entrada (e saída) de caixa é contabilizada no sistema, porém não conseguimos realizar o teste de aderência no caixa.

Vale ressaltar a dificuldade em administrar os recursos da entidade, pois ela não possui uma receita fixa por mês, já que depende de doações. As doações, geralmente, são feitas por depósitos em conta corrente e pagamentos de boletos.

No entanto, existe uma preocupação grande em fazer o hospital se sustentar independentemente das receitas de doações. Estas são vistas como uma forma deaumentar os benefícios para o paciente, não como forma de custeamento do tratamento. Por fim, o último indicador é o número de casos novos, no qual verifica-se a penetração da fundação na sociedade.

M esmo com essa dificuldade, a entidade não apresenta problemas com disponível. A contabilidade é realizada internamente por fluxo de caixa, porém é um contador terceirizado que assina as demonstrações contábeis. Como já citado, a entidade é auditada por auditores independentes. Segundo a controller ${ }^{23}$ da entidade, a contabilidade reflete a real situação da empresa.

\section{Consideraçõesfinais}

Este estudo teve como objetivo observar a eficiência dos testes de controle interno, aplicada em uma estrutura organizacional pertencente ao terceiro setor, verificando a confiabilidade nos relatórios contábeis, financeiros e operacionais.

Durante a realização do estudo, observou-se que existem mecanismos de controle estruturado na instituição, porém a execução desses controles deixa a desejar. Percebe-se que o nível de controle interno está estritamente ligado à sua estrutura organizacional.

Por se tratar de uma ONG na área de saúde, na maioria das vezes a execução dos controles é feita de maneira amadora pelos voluntários, que são pessoas não especializadas, assim acabam tomando decisões baseadas na boa vontade, esquecendo-se das práticas efetivas de controle.

Outro ponto importante é que a entidade deposita uma grande confiança em seus voluntários, o que pode gerar margem para falhas na execução dos controles internos, ou até mesmo a ocorrência de fraudes.

Algumas recomendações que amenizem esse problema de controle interno nas entidades do terceiro setor seriam recrutar pessoal especializado na composição do voluntariado, além da utilização de treinamento do pessoal com o intuito de disseminar uma cultura de controle, transparência e responsabilidade.

Os resultados deste estudo de caso sinalizam tendências da necessidade de mai or controle interno nas organizações do terceiro setor, em especial com vistas a salvaguardar os interesses, a confiabilidadenos relatórios contábeis, financeiros e operacionais dentro dos procedimentos estabelecidos pelas fundações.

N este estudo de caso em si, pode-se observar que a premissa é verdadeira: o nível da estrutura organizacional interfere, sim, nas práticas decontrole interno da entidade. Evidentemente, por se tratar de um estudo de caso, os resultados não podem ser generalizados para todas as organizações do terceiro setor. 


\section{Colaboradores}

CAG Bonacim, AL Salgado, LS Girioli e AM P Araujo participaram igualmente de todas as etapas de elaboração do artigo.

\section{Referências}

1. M elo VP, Fischer T, Soares Jr JS. Diversidades e confluências no campo do terceiro setor: um estudo de organizações baianas. In: Anais do XXVII Encontro da Associação Nacional de Programas de Pós-Graduação em Administração (ENAN PAD). Atibaia: AN PAD; 2003.

2. Teixeira RF. Discutindo o terceiro setor sob o enfoque de concepções tradicionais e inovadoras de administração. Caderno de Pesquisas em Administração 2004; 11(1):1-15.

3. Fischer $R M$, Bose $M, M$ endonça $L R$, Fedato $C$ M onitoramento de projetos sociais: um desafio para as alianças intersetoriais. In: Anais do XXVII Encontro da Associação Nacional de Programas de Pósgraduação em Administração (ENAN PAD). Atibaia. ANPAD; 2003.

4. Falconer AP. A promessa do terceiro setor: um estudo sobre a construção do papel das organizações sem fins lucrativos e do seu campo de gestão [dissertação]. São Paulo: Universidade de São Paulo; 1999.

5. Santos RC. M ensurando valor e performance na prestação de serviços sociais. Revista Eletrônica de Gestão Organizacional [periódico na Internet] 2004; 2(1). [acessado 2007 set 28]. Disponível em: www. gestaoorg.dca.ufpe.br

6. Leeder SR. Valuable health: what do we want, and how do we get it? Australian Journal of Public $\mathrm{H}$ ealth 1992; 16(2):8-24.

7. Bossert T, Larranaga $O$, Ruiz M eir F. Descentralización de los sistemas de salud en América Latina. Revista Panamericana Salud Publica 2000; 8(1-2):84 92.

8. O mapa dos hospitais: empreendimentos privados perdem espaço. Gazeta M ercantil 2006; jun 27. p. A-10.

9. Carr-Hill R. Allocating resources to health care: RAWP is dead: long live RAWP. Health Policy 1989; 7(13):133-144.

10. Matos CA, Pompeu JC. Onde estão os contratos? Análise da relação entre os prestadores de serviços privados e o SUS. Cien Saude Colet 2003; 8(2):629644

11. Coelho SCT. Terceiro setor: um estudo comparativo entre Brasil e Estados U nidos. São Paulo: Senac; 2000.

12. Fernandes RC. Privado, porém público: o terceiro setor na América Latina. 3a ed. Rio de Janeiro: Relume-Dumará; 2002.
13. Tenório FG, organizador. Gestão de ONGs: principais funções gerenciais. 5a ed. Rio de Janeiro: FGV 2001.

14. Tachizawa T. Gestão ambiental e responsabilidade social corporativa: estratégias de negócios focada na realidade brasileira. São Paulo: Atlas; 2002.

15. Roesch SM A. Gestão de ONGs: rumo a uma agenda de pesquisas que contemple a sua diversidade. In: Anais do ENAN PAD. Salvador; 2002.

16. NBC T11 - Normas de Auditoria Independente das Demonstrações Contábeis. [documento da Internet]. 1997[acessado 2007 jul 20]. Disponível em: http://www.portaldecontabilidade.com.br/nbc/ t11.html

17. Almeida MC. Auditoria: um moderno curso e completo. 5a ed. São Paulo: Atlas; 1996.

18. Beuren IM. Como elaborar trabalhos monográficos em contabilidade: teoria e prática. 3a ed. São Paulo: Atlas; 2006.

19. Martins GA. Estudo de caso: uma estratégia de pesquisa. 2a ed. São Paulo: Atlas; 2008.

20. Richardson RJ. Pesquisa social: métodos e técnicas. 3a ed. São Paulo: Atlas; 1999.

21. Beal A. Procedimentos de auditoria para avaliação dos controles internos na área de licitaç̃es e contratos. Brasília: Tribunal de Contas da União; 2000. [acessado 2007 jul. 27]. Disponível em: http://www2. tcu.gov.br/pls/portal/docs/page/tcu/publicacoes/ classificacaoporassunto/auditoria/pa\% 20de $\% 20$ controles\%20internos.doc

22. Instituto Brasileiro de Contadores (Ibracon). Curso básico de auditoria. São Paulo: Atlas; 1996.

23. Borinelli $M L$, Rocha W. Práticas de controladoria: um estudo nas cem maiores empresas privadas que atuam no Brasil. In: 70 Congresso USP de Controladoria e Contabilidade. São Paulo: 2007.

Artigo apresentado em 14/05/2008

Aprovado em 07/08/2009

Versão final apresentada em 11/08/2009 